http://dx.doi.org/10.32929/2446-8355.2019v28n1p82-96

\title{
DIVERSIFICAÇÃO PRODUTIVA COMO ESTRATÉGIA DE APOIO À SEGURANÇA ALIMENTAR E NUTRICIONAL ENTRE OS AGRICULTORES FAMILIARES NA CAMPANHA GAÚCHA
}

\author{
Shirley Grazieli da Silva Nascimento ${ }^{1 *}$, Verusca Espinosa Mancilha ${ }^{2}$, Daniel Hanke ${ }^{3}$, \\ Cláudio Becker ${ }^{4}$, Mariana Rockenbach de Ávila ${ }^{5}$
}

\footnotetext{
${ }^{1}$ Dra. Em Agronomia, Professora Adjunta da Universidade Federal do Pampa/ Dom Pedrito -RS. *E-mail: shirleynascimento@unipampa.edu,.br

${ }^{2}$ Tecnóloga em Agronegócio. Universidade Federal do Pampa/ Dom Pedrito -RS.

${ }^{3}$ Dr. Em Ciência do Solo, Professor Adjunto da Universidade Federal do Pampa/ Dom Pedrito -RS.

${ }^{4}$ Dr. Em Agronomia, Professor Adjunto da Universidade Estadual do Rio Grande do Sul/ Santana do Livramento - RS.

${ }^{5}$ Dra. Em Zootecnia, Professora Substituta da Universidade Federal do Pampa/ Dom Pedrito -RS.
}

\section{Recebido: 23/10/2018; Aceito: 02/04/2019}

RESUMO: O objetivo principal deste trabalho foi investigar as estratégias de diversificação produtiva utilizadas pelos agricultores familiares do município de Dom Pedrito/RS, para assegurar a Segurança Alimentar e Nutricional (SAN) da população em geral. Foram apontados os desafios e limites para se consolidar esta estratégia. Para esta investigação, foram realizadas entrevistas com 15 agricultores familiares do município entre os meses de março a maio de 2018. Foram estudados aspectos sociais e produtivos dos agricultores familiares e como se dá a produção nesses estabelecimentos, observando-se semelhanças entre as famílias entrevistadas. O sistema de produção manual, a mão de obra totalmente familiar utilizada para a produção agrícola e pecuária, e a comercialização direta ao consumidor em comércios locais, na feira livre municipal e nos programas PAA e PNAE estão entre essas semelhanças. Apesar de haver uma grande diversificação produtiva entre os agricultores familiares da região, verificou-se que estes não sabem o significado do termo Segurança Alimentar e Nutricional, e que a motivação que leva-os a diversificar a produção é a necessidade econômica de produzir mais em razão da demanda dos consumidores, possibilitando assim, um incremento da receita obtida em moeda.

Palavras-chave: Alimentação saudável. Variedade de alimentos. Produção de base familiar.

\section{PRODUCTIVE DIVERSIFICATION AS A STRATEGY TO SUPPORT FOOD AND NUTRITIONAL SAFETY BETWEEN FAMILY FARMERS IN THE BRAZILIAN STATE OF RIO GRANDE DO SUL}

\begin{abstract}
The main objective of this work was to investigate the productive diversification strategies used by the Family Farmers of the municipality of Dom Pedrito / RS, to ensure the Food and Nutrition Security of the population in general. The challenges and limits to consolidate this strategy were pointed out For this investigation, informal interviews have been applied to family farmers between April and May 2018. Social and
\end{abstract}


productive aspects of family farming were studied, as well as the production of these farms. Somo similarities between the family farming or this region are: i) the manual production system; ii) the totally human familiar workforce used for agricultural and livestock production; iii) direct marketing to the consumer in local trades, as well as to the PAA / PNAE governmental programs . Although there is great diversification of production between family farmers in the region, they do not know the term Food and Nutrition Security meaning. The farmers motivation to diversify production is the economic need to produce more in consumer demand, thus enabling an increase in financial income.

Key words: Healthy eating. Variety of food. Family-based production.

\section{INTRODUÇÃO}

O Rural Brasileiro tem sido amplamente discutido nos dias atuais (BUAINAIN et al., 2013). Neste sentido, surgem várias temáticas acerca do tema. Entre elas, a agricultura familiar, que não é exatamente um assunto novo, mas uma definição sempre em evolução, com muitas raízes históricas. Na literatura, há autores que consideram a moderna agricultura familiar como uma nova categoria, formada pelas transformações das sociedades capitalistas e "gestada a partir dos interesses e das iniciativas do Estado" (citado por ALTAFIN, 2007, p. 1).

Dentro da definição de que a Agricultura Familiar está em constante evolução (Souza et al., 2015), percebe-se que a característica típica dessa forma de produção social - para consumo - vem perdendo lugar para a produção das commodities. Isso se deve, principalmente, ao progresso tecnológico característico do processo de modernização conservadora da agricultura, pautada nos interesses do capitalismo, que ao mesmo passo em que possibilitou a obtenção de maior lucratividade, causou a exclusão das pessoas do campo e contribuiu fortemente para a degradação ambiental e social das populações (ALTEMBURG; BEZERRA; SCHWENGBER, 2015).

Segundo Ribeiro (2009), em termos de estrutura fundiária, de formação cultural e de tipo de agricultor familiar, a região sul do Rio Grande do Sul apresenta uma realidade diferenciada, predominando propriedades compostas por grandes extensões de áreas.

No Brasil, a área plantada de grandes monoculturas, segundo relatório do Conselho Nacional de Segurança Alimentar e Nutricional - CONSEA (2010), aumentou consideravelmente em relação à área ocupada pelas culturas de menor porte, direcionadas ao abastecimento interno. Um exemplo desse fato é que apenas quatro culturas de larga escala (milho, soja, cana e algodão), no ano de 1990, ocupavam quase o dobro da área ocupada por outros 21 cultivos.

Esse cenário de incentivo à expansão de monoculturas em território brasileiro continua crescente (BURITY, 2010), causando preocupações com a perda de diversidade genética, visto que, a conservação da biodiversidade é fundamental para a manutenção do equilíbrio de diversas espécies no planeta (FERREIRA et al., 2005). 
Uma das consequências desse aumento é o incremento no uso de agrotóxicos, o que situa o Brasil como o maior mercado de agrotóxicos do mundo atualmente, verificando um aumento nos registros de intoxicações na mesma proporção (CONSEA, 2010).

Outra definição muito discutida ultimamente é a de segurança alimentar, especialmente a partir de 1999, quando o Ministério da Saúde instituiu a Política Nacional de Alimentação e Nutrição (PNAN), integrando a Política Nacional de Saúde. A partir daí, surgem várias discussões acerca do assunto Segurança Alimentar e Nutricional (SAN) no Brasil.

Quando citamos o cenário alimentar mundial, Altemburg (2014) relata ainda que este vem passando por diversas transformações, que remetem a um processo de transição nutricional, que mostra a desvalorização da alimentação e das formas saudáveis de produção. No entanto, Food and Agriculture Organization of the United Nations (FAO) estabelece que os países produzam alimentos adequados e com qualidade, possibilitando a segurança alimentar das populações (MANIGLIA, 2009).

Dentro desse contexto, mudanças estruturais, sociais e econômicas vêm atingindo o meio rural da Campanha Gaúcha, alterando a realidade produtiva da agricultura familiar da atualidade, que passa a ter uma participação na produção de commodities, a exemplo da soja. Conforme Costa e Mainardi (2017), o município de Dom Pedrito, nos últimos anos, superou e quase dobrou a área plantada, e já desponta como um grande produtor de soja, figurando entre os 10 maiores municípios em área plantada (EMBRAPA, 2014).

De acordo com Penteado (2012), estratégias de diversificação produtiva, tais como policulturas, rotações, cultivos de cobertura e integração animal, são a base da agricultura ecológica, a fim de melhorar a produtividade e garantir a saúde do ecossistema. A agricultura familiar é a responsável por grande parte da produção de alimentos no país, sendo que quase a totalidade da sua produção é destinada ao mercado interno. Todavia, o fortalecimento da agricultura familiar é estratégico para garantir a segurança e soberania alimentar e nutricional da população (CONSEA, 2010).

Dessa forma, este trabalho tem como objetivo investigar as estratégias de diversificação produtiva utilizadas pelos agricultores familiares do município de Dom Pedrito/RS campanha gaúcha meridional apontando seus desafios e limites.

\section{MATERIAL E MÉTODOS}

Para a realização deste trabalho, optou-se por uma pesquisa qualitativa, de caráter exploratório, a fim de levantar dados sobre a forma de diversificação produtiva e o conhecimento dos agricultores familiares acerca do tema Segurança Alimentar e Nutricional. Segundo Gil (2008, p.26), define-se pesquisa como "o processo formal e sistemático de desenvolvimento do método científico".

Trata-se de uma pesquisa realizada em três etapas distintas. Na primeira etapa, foi realizada uma revisão de literatura referente ao tema, com o propósito de compreender o processo histórico do tema no Brasil, tanto no que diz respeito à Agricultura Familiar, quanto à Segurança Alimentar e Nutricional. 
A segunda etapa constituiu-se da pesquisa de campo, onde foram realizadas entrevistas com agricultores familiares do município de Dom Pedrito/RS. Para Minayo (1996), o trabalho de campo consiste no recorte empírico da construção teórica elaborada no momento. Essa etapa combina entrevistas, observações, levantamentos de material documental e bibliográfico, instrucional.

A terceira etapa deste trabalho constituiu-se em realizar a análise textual de discurso (MORAES; GALIAZZI, 2016) das entrevistas. Esta técnica é utilizada para auxiliar na leitura multidimensional de compreensão da realidade social. Os resultados foram divididos em três grandes categorias: a) Preocupação com a segurança alimentar; b) Responsabilidade com o meio ambiente e c) Diversificação produtiva.

O universo de estudo foram propriedades agrícolas familiares do município de Dom Pedrito/RS. Segundo o IBGE (2010), o município apresenta uma população de 35.275 habitantes na zona urbana e somente 3.623 na zona rural, com 717 estabelecimentos familiares.

A coleta de dados foi realizada no período de janeiro a março de 2018, através de uma entrevista com quinze (15) agricultores familiares em suas propriedades rurais (Figura 1), a fim de compreender o universo destes e apreender informações contidas nas falas desses atores sociais. Os agricultores foram escolhidos de maneira aleatória, em diferentes locais representativos do município, de maneira que pudéssemos abranger uma maior quantidade de localidades para realizar as entrevistas. Para a realização da análise dos dados, os mesmos foram selecionados, agrupados em categorias, de modo a facilitar as análises e considerações.

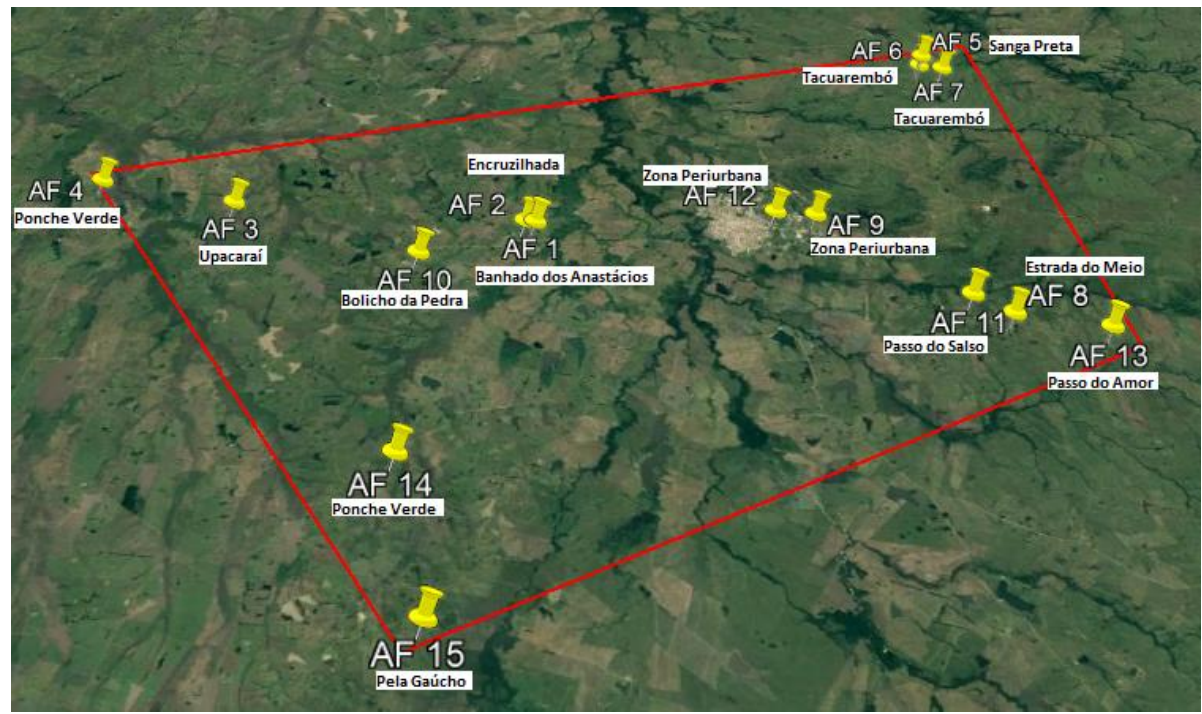

Figura 1. Localidades visitadas no município de Dom Pedrito, RS. Locations visited in the municipality of Dom Pedrito, RS.

Fonte: Elaborado pelos autores a partir do Google Earth.

A técnica de amostragem utilizada foi a não probabilística por conveniência (membros da amostra que estejam mais acessíveis ao entrevistador), ou seja, agricultores que se disponibilizaram a responder as questões propostas (GIL, 1991). A Figura 1 expressa as localidades visitadas, ilustrando através de marcadores, cada um dos agricultores familiares. 
Para ilustrar os produtos cultivados citados pelos agricultores entrevistados, utilizamos o recurso Nuvem de palavras através do software Nvivo 10 na qual agrupa e organiza graficamente as palavras em função da sua frequência.

Procurou-se visitar o maior número possível de propriedades por localidade, visando entender detalhes, experiências e características da agricultura familiar. Buscou-se compreender também, como se relacionam entre si e com seus consumidores. As localidades visitadas no município foram: i) Banhado dos Anastácio; ii) Encruzilhada; iii) Upacaraí; iv) Ponche Verde; iv) Sanga Preta; v) Tacuarembó; vi) Estrada do Meio; vii) Zona Periurbana; viii) Bolicho da Pedra; ix) Passo do Salso; x) Passo do Amor e; xi) Pela Gaúcho.

\section{RESULTADOS E DISCUSSÃO}

A partir das imersões a campo foi possível conhecer um pouco da realidade da agricultura familiar no município de Dom Pedrito/RS, ou seja, quem são os trabalhadores, a forma como produzem, o que produzem e para quem.

Um dos itens investigados foi a extensão das propriedades familiares. Foi constatado que grande parte das propriedades apresentam menos de 20 hectares, representando menos de um módulo fiscal.

A Figura 2 expressa o tamanho das propriedades familiares, em hectares.

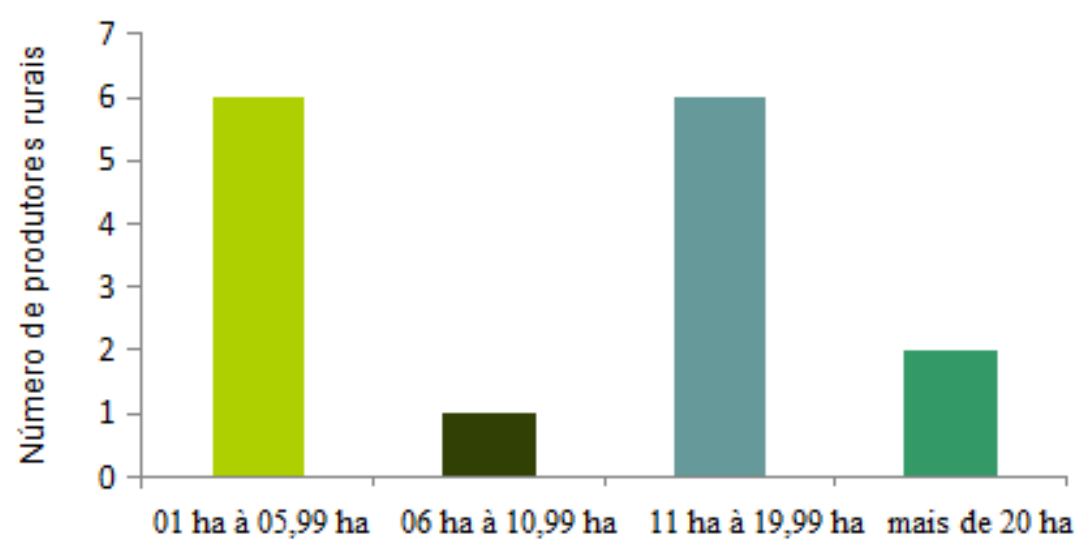

Figura 2. Tamanho das unidades de produção familiar analisadas (em hectare). Size of family production units analyzed (in hectare).

Com relação ao tamanho das propriedades, as mesmas variam de 01 a 70 hectares, sendo identificado que, quanto menor a propriedade, maior a diversidade produtiva, conforme relato do Agricultor 3: [...] "temos que ter produção para o ano todo."

Foi observado que nenhum dos agricultores familiares relatou ter funcionário. Esse fato se deve às dificuldades de contratação de mão-de-obra, alegando-se que, "sobra pouco recurso financeiro". Assim, o universo de estudo é caracterizado como mão de obra exclusivamente familiar.

Embora o processo de masculinização do rural seja uma realidade (BRUMER, 2004), um fato que chamou atenção foi de propriedades onde somente trabalha a proprietária, o que 
ratifica a ideia de que o número de mulheres frente às atividades agrícolas cresce a cada ano nessa região. Nesta propriedade a mão de obra é somente da mulher, a mesma relatou o desejo de aumentar a sua produção (mesmo esta não sendo pequena para uma pessoa sozinha cultivar), mas que não teria condições de contratar funcionário, uma vez que a carga tributária é muito alta.

Além disso, esbarra na questão de que é muito alta, e ainda, pela dificuldade que é nos dias atuais, encontrar uma "pessoa boa": [...] "a gente bem que queria plantar mais, mas não temos muita força em função da idade. Não dá pra ter funcionário, senão não sobra nada, é muito imposto que tem que pagar" (Agricultor 2 - Encruzilhada).

Outro dado relevante é que quase não há filhos trabalhando com os pais (Quadro 1), o que muito preocupa quando se pensa em sucessão familiar, confirmando o apresentado por Matte, Spanevello; Andeatta (2015), uma vez que a população rural está envelhecendo, e os jovens migrando para a zona urbana.

Tabela 1. Mão de obra familiar nas propriedades. Household labor on rural properties.

\begin{tabular}{c|c|c}
\hline Entrevistado & Localidade & Quem trabalha \\
\hline Agricultor 1 & Banhado dos Anastácio & Proprietária \\
\hline Agricultor 2 & Encruzilhada & Casal proprietários \\
\hline Agricultor 3 & Upacarai & Proprietário \\
\hline Agricultor 4 & Ponche Verde & Proprietário e irmão \\
\hline Agricultor 5 & Sanga Preta & Proprietário \\
\hline Agricultor 6 & Tacuarembó & Casal proprietários e sogra \\
\hline Agricultor 7 & Tacuarembó & Casal proprietários \\
\hline Agricultor 8 & Estrada do Meio & Proprietário e filho \\
\hline Agricultor 9 & Zona periurbana & Proprietário e filho \\
\hline Agricultor 10 & Bolicho da Pedra & Proprietária e filho \\
\hline Agricultor 11 & Passo do Salso & Proprietário \\
\hline Agricultor 12 & Zona Periurbana & Proprietário \\
\hline Agricultor 13 & Passo do Amor & Casal proprietários \\
\hline Agricultor 14 & Ponche Verde & Casal proprietários \\
\hline Agricultor 15 & Pela Gaúcho & Proprietária \\
\hline
\end{tabular}

De acordo com o ilustrado na tabela 1, verificou-se que entre os agricultores, somente em três deles relataram que os filhos ainda permanecem nas propriedades, e tem intenção de dar continuidade à produção familiar, a exemplo do relato [...] "o pai antes, só tinha gado e leite, a horta era só pra nós, agora, resolvi pegar a parte da horta e começamos vender, e eu fiquei com essa parte" (Agricultor 8 - Estrada do meio), e ainda: “ eu me criei aqui, gosto muito do campo, fiz faculdade de gestão ambiental e agora que a mãe tá ficando velhinha, eu quero cuidar de tudo" (Agricultor 10 - Bolicho da Pedra) .

Entre os entrevistados, somente um disse não cultivar hortaliças em sua propriedade, apesar de ter este tipo de produção em sua propriedade, como mostra o relato: [...] "não sou agricultor, estou virando agricultor porque comprei a área agora, de uns herdeiros que não 
queriam continuar" (Agricultor 1 - Banhado dos Anastácio), retificando mais uma vez o problema da sucessão familiar.

Entre os agricultores entrevistados que cultivam horta, somente um deles não comercializa a produção, relatando que [...] "não tenho prática com outra coisa a não ser com pecuária, daí a gente fica com medo" (Agricultor 5 - Sanga Preta), que apesar de possuir uma horta, utiliza somente para consumo da família e para os animais da propriedade.

Para a questão da comercialização das hortaliças, verifica-se que a grande maioria, utiliza como renda a comercialização dos excedentes destes produtos, o que é característico da agricultura familiar.

Apesar das propriedades serem em sua maioria relativamente pequenas (variando de 01 ha à $05 \mathrm{ha}$ ) verificou-se substancial diversificação na produção no presente estudo, salientando-se que, quanto menor a propriedade, mais diversificada ela é. A abordagem da diversificação produtiva pode auxiliar no incremento de renda dos produtores rurais e minimizar os riscos da produção (NIEHOF, 2004).

Enquanto a maior parte dos agricultores produzem hortaliças comumente consumidas pela população: couve, alface, tempero verde, surpreendentemente, o agricultor com menor espaço na propriedade, relatou cultivar produtos dos mais diferenciados, como: nogueira, avelã, acelga, pêssego, rúcula, sálvia, pimenta, canela-do-mato, entre outras.

A Figura 3 a seguir, mostra a menor propriedade visitada, e sua diversidade produtiva.

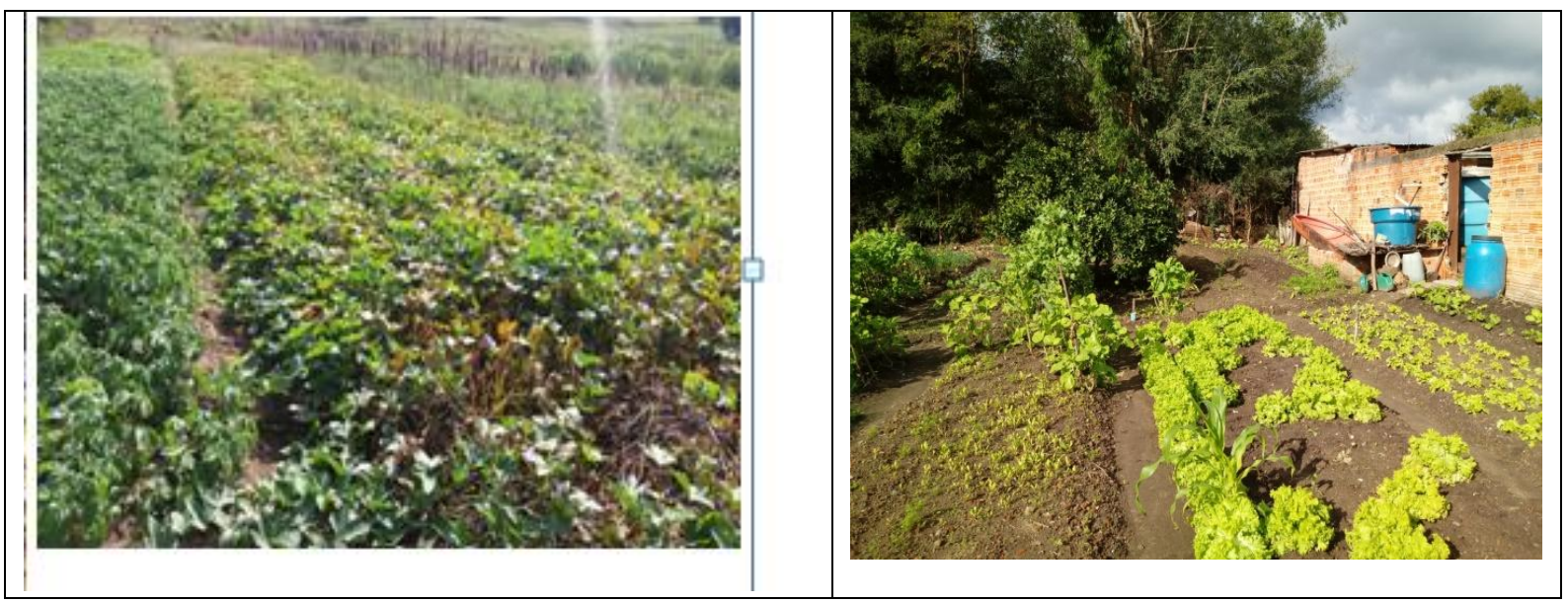

Figura 3. Fotografias das propriedades de produção familiar na localidade Bolicho da Pedra/Dom Pedrito/RS. Photographs of the family production in the locality of Bolicho da Pedra - Dom Pedrito/RS.

Conforme relato da agricultora, embora o espaço seja pequeno, é todo aproveitado, através de rotação de culturas, [...] "produzimos de tudo, de acordo com o que o pessoal vai pedindo, a gente vai plantando, temos que agradar toda a freguesia, e quando a gente faz o que gosta, nem é trabalho" (Agricultor 10 - Bolicho da Pedra).

Para ilustrar os produtos cultivados citados pelos agricultores entrevistados, utilizamos o recurso Nuvem de palavras em tamanho, referente à frequência de menção, conforme Figura 4. 
Através da Nuvem de palavras, observou-se que, apesar de diversificados, a grande maioria dos agricultores cultivam os mesmos tipos de produtos. Foi observado um grande destaque aos seguintes produtos: i) tempero verde; ii) alface; iii) couve; iv) beterraba e; v) milho.

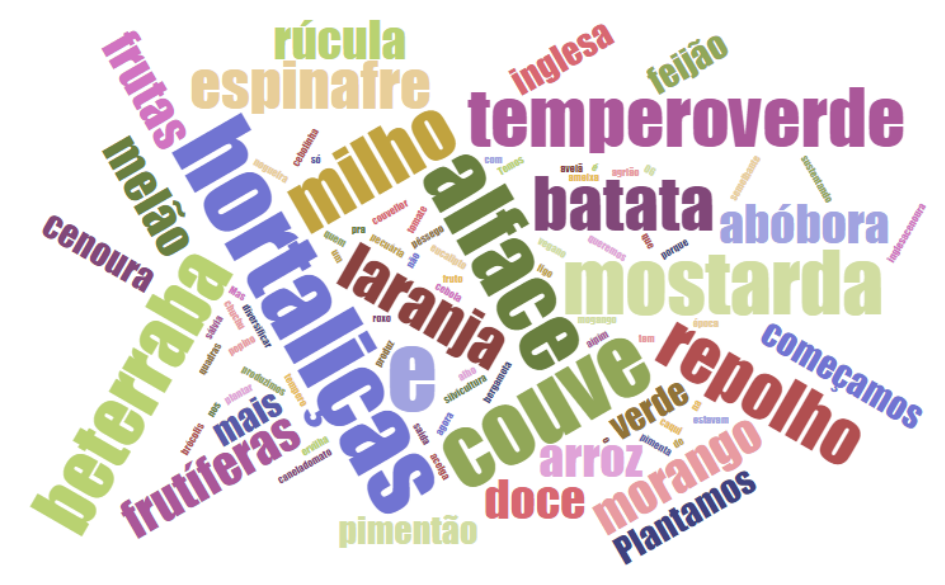

Figura 4. Nuvem de palavras dos produtos cultivados. Word cloud of cultivated products.

Quanto ao destino dessa produção, grande parte dos entrevistados vende em comércios da cidade, direto ao consumidor de maneira informal e na feira livre municipal. Além dos agricultores que participam do Programa Nacional de Alimentação Escolar (PNAE) e Programa de Aquisição de Alimentos (PAA). O gráfico 4 a seguir mostra o destino da produção.

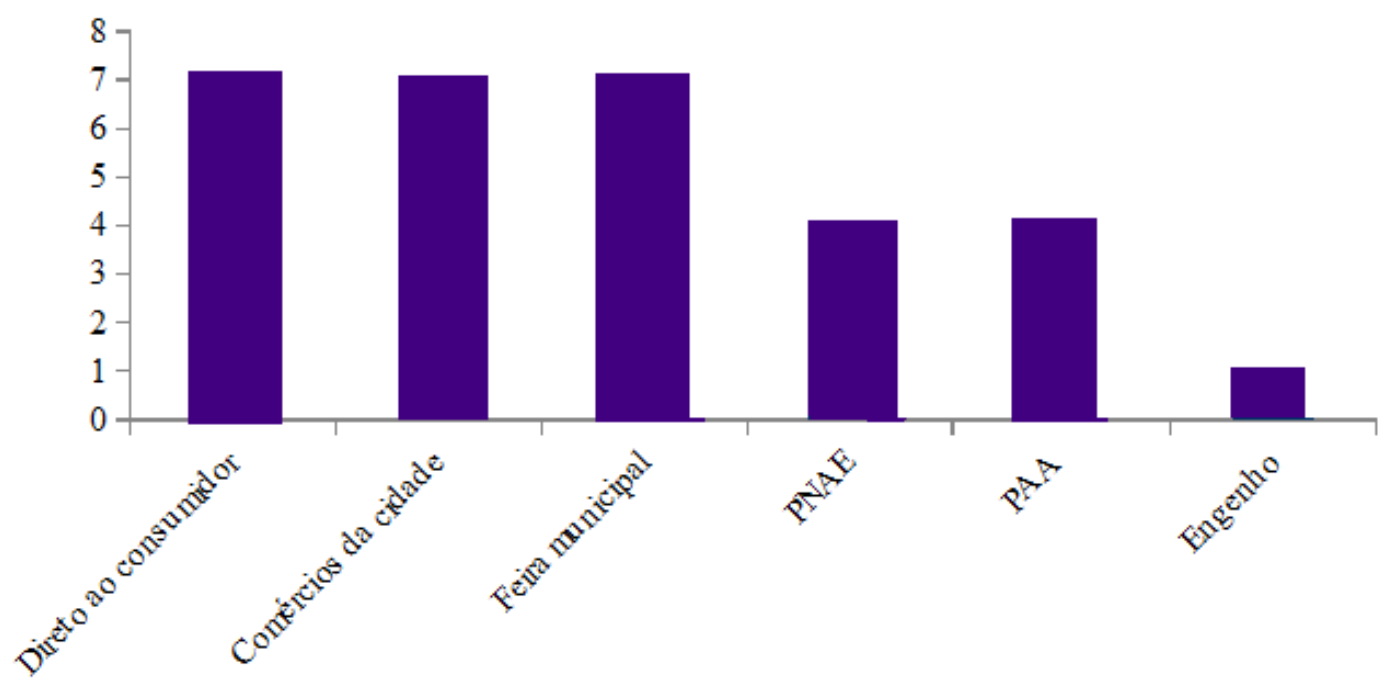

Figura 5. Destino dos alimentos produzidos nas propriedades. Destination of food produced on rural properties.

Dentre as formas de comercialização, percebe-se que o acesso aos mercados institucionais como PNAE e PAA estão satisfazendo as expectativas dos agricultores entrevistados, como mostra excerto: [...] "eles nos pagam muito bem, melhor que se a gente fosse vender nos mercados, faz anos que eu entrego nas escolas, e enquanto eu puder, vou continuar” (Agricultor 15 - Pela gaúcho). 
Corroborando com as discussões acerca do PNAE no município de Dom Pedrito, podemos analisar, através da tabela 2 abaixo, que o PNAE, embora seja um programa importante para os agricultores, está sendo desarticulado no município de Dom Pedrito. Como pode ser observado na tabela abaixo, o programa que começou a emplacar no ano de 2012 e se manteve crescente até 2015 teve uma grande baixa no ano de 2016, configurando um retrocesso para segurança alimentar e a agricultura familiar em nosso país. Esta situação se torna ainda mais preocupante com os encaminhamentos do atual governo em relação ao CONSEA ${ }^{1}$.

Tabela 2. Aquisição de Produtos da Agricultura Familiar em Dom Pedrito. Acquisition of Family Agriculture Products in Dom Pedrito.

\begin{tabular}{rrrc}
\hline Ano & Transferido & $\begin{array}{c}\text { Adquirido da } \\
\text { Agricultura Familiar }\end{array}$ & Percentual \\
\hline 2011 & $239.520,00$ & - & $0 \%$ \\
2012 & $273.132,00$ & $70.538,54$ & $25,83 \%$ \\
2013 & $284.560,00$ & $100.676,50$ & $35,38 \%$ \\
2014 & $398.862,00$ & $131.900,84$ & $33,07 \%$ \\
2015 & $345.314,00$ & $168.305,38$ & $49 \%$ \\
2016 & $24.441,64$ & 760,00 & $3,11 \%$ \\
\hline
\end{tabular}

Fonte: Fundo Nacional de Desenvolvimento da Educação (2018).

Quanto a forma de produção, dos 15 agricultores entrevistados, 09 realizam todas as operações de forma manual (preparo do solo, ajustes no dossel de plantas, operações de colheita e pós-colheita). Os demais, utilizam algum tipo de implemento mecânico para auxiliar na produção, sendo que uma produtora que trabalha sozinha em seu estabelecimento, conta com o auxílio da prefeitura municipal, que prepara a terra e faz a semeadura, sendo somente o cuidado e a colheita realizados de forma manual, conforme relato: [...] "a gente tem uma parceria com a prefeitura, que prepara a terra, vem com a semeadeira. A colheita sim, é tudo manual.” (Agricultor 14 - Pela Gaúcho).

E quanto à diversificação produtiva, três agricultores relataram que não diversificam a produção, em função das seguintes questões: i) falta de espaço; ii) ausência de mão de obra; iii) falta de prática e; iv) insegurança com a produção de outras culturas. Os demais agricultores, procuram diversificar sua produção, de acordo com a estação do ano, como por exemplo, o plantio de culturas anuais de verão, principalmente milho, mandioca, hortaliças e frutíferas estivais. Em relação às pastagens, as mesmas são utilizadas durante todo o ano, mescla-se o campo nativo com espécies exóticas de inverno e verão.

Entretanto, a maioria desses agricultores procura atender às necessidades dos consumidores, realizando inclusive pesquisas de mercado. Os agricultores que participam do PNAE e PAA diversificam a produção em função do que é solicitado pelas escolas e pela unidade local do Exército Brasileiro.

\footnotetext{
${ }^{1} \mathrm{O}$ atual presidente Jair Bolsonaro aprovou o desmonte do Conselho Nacional de Segurança Alimentar e Nutricional - CONSEA. Este fato tem causado inúmeras discussões no Brasil, pois fere questões de ordem legislativa e atua no contra-movimento que o país, através de seus governos, vinham cunhando para garantir segurança e soberania alimentar.
} 
"começamos a diversificar com as hortaliças, que antes a gente não plantava, porque tivemos muito problema com o leite, que era entregue, mas não nos pagavam em dia. Daí acaba cansando, porque a gente precisa, vive disso" (Agricultor 8 - Estrada do Meio) .

Tabela 2. Produção pecuária nos estabelecimentos. Livestock production in establishments.

$\begin{array}{ccc}\text { Entrevistado } & \text { Produção Pecuária } & \text { Quais } \\ \text { Agricultor 1 } & \text { Sim } & \text { Equinos } \\ \text { Agricultor 2 } & \text { Não } & - \\ \text { Agricultor 3 } & \text { Sim } & \text { Bovinos, ovinos e suínos } \\ \text { Agricultor 4 } & \text { Sim } & \text { Bovinos e ovinos } \\ \text { Agricultor 5 } & \text { Sim } & \text { Bovinos e ovinos } \\ \text { Agricultor 6 } & \text { Sim } & \text { Bovinos e ovinos } \\ \text { Agricultor 7 } & \text { Sim } & \text { Ovinos } \\ \text { Agricultor 8 } & \text { Sim } & \text { Bovinos e ovinos } \\ \text { Agricultor 9 } & \text { Não } & - \\ \text { Agricultor 10 } & \text { Não } & - \\ \text { Agricultor 11 } & \text { Sim } & \text { Ovinos } \\ \text { Agricultor 12 } & \text { Não } & - \\ \text { Agricultor 13 } & \text { Sim } & \text { Aves e suínos } \\ \text { Agricultor 14 } & \text { Sim } & \text { Bovinos } \\ \text { Agricultor 15 } & \text { Sim } & \text { Bovinos }\end{array}$

Entre a diversificação dos agricultores entrevistados, verifica-se a produção pecuária. Nas propriedades estudadas, há produção de bovinos, ovinos, equinos, suínos e aves. A Tabela 2 a seguir ilustra o tipo de produção pecuária existente em cada um dos estabelecimentos.

Quadro 2. Motivos (ou não) da produção pecuária nos estabelecimentos familiares. Reasons (or not) for livestock production in family farms.

\begin{tabular}{|l|l|}
\hline \multicolumn{1}{|c|}{ Excerto do relato } & Identificação \\
\hline $\begin{array}{l}\text { [...] bem que nós queria criar uns bichinhos pra ajudar } \\
\text { na nossa renda, porque se não fosse a aposentadoria, } \\
\text { não ia dar pra viver só com a renda do que plantamos } \\
\text { aqui fora. }\end{array}$ & Agricultor 2: Encruzilhada \\
\hline $\begin{array}{l}\text { [...] a gente vende o gadinho para ajudar na nossa } \\
\text { renda, porque não dá pra contar só com a } \\
\text { aposentadoria. A gente é velho, e quando menos } \\
\text { espera adoece, então tem que ter uma reservinha. }\end{array}$ & Agricultor 4: Ponche Verde \\
\hline $\begin{array}{l}\text { [...] sempre é bom ter um gadinho pra vender se a } \\
\text { gente se aperta, e no frigorífico é dinheiro na mão. }\end{array}$ & Agricultor 8: Estrada do meio \\
$\begin{array}{l}\text { Imagina se acontece alguma coisa, se 'Deus o livre" } \\
\text { vem um temporal e acaba com tudo, temos que ter pra } \\
\text { onde recorrer. }\end{array}$ & \\
\hline
\end{tabular}


Entre os entrevistados, $73 \%$ utilizam a criação pecuária como fonte de renda, seja como única fonte ou como fonte de renda extra, ou para situações de necessidade, utilizando a produção pecuária como uma forma de diversificação produtiva.

O Quadro 2 faz um recorte de depoimentos de agricultores entrevistados, expressando os motivos da utilização da criação pecuária nos estabelecimentos, todos os agricultores relataram que a pecuária serve como fonte de renda, tanto bovinos, quanto ovinos, e a maioria vende direto ao consumidor, ou ainda, cria e recria.

A produção pecuária está presente na maioria das propriedades, principalmente a bovinocultura de corte e leite (Tabela 1). Embora alguns dos entrevistados relatarem a sua decepção com a produção leiteira, nunca pensaram em acabar com a produção pecuária, que, segundo eles, é "um a mais".

Quanto à destinação da produção pecuária, perguntou-se aos entrevistados se utilizam a produção como receita ou para consumo próprio. Foi verificado que a maioria deles busca complementar a renda da produção agrícola com a produção animal, conforme apresentado por Ribeiro (2003), como por exemplo, o Agricultor 7 - Tacuarembó: [...] "vendemos no Natal, para aumentar um pouco a nossa renda", ou ainda [...] "a gente cria pra ter outra fonte de renda, e vende no frigorífico quando precisa de um dinheirinho, por que ali, 'é dinheiro na mão'” (Agricultor 9 - Estrada do Meio). A Figura 6 a seguir ilustra a percentagem de agricultores que utilizam a produção como renda ou para consumo próprio.

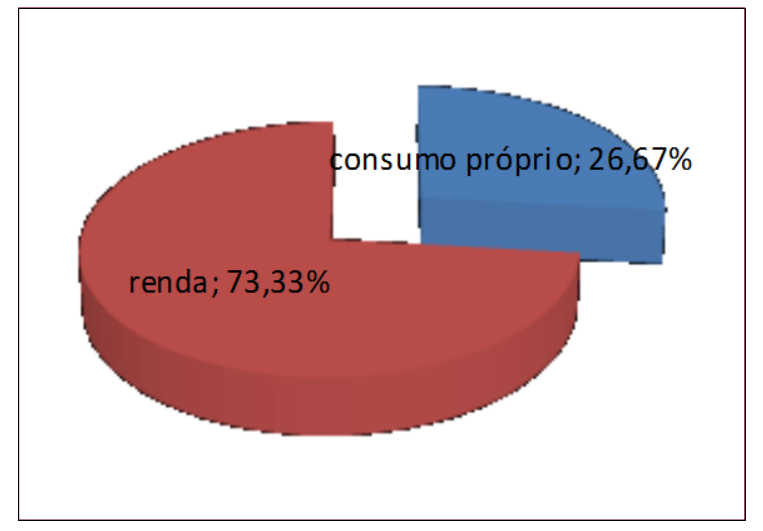

Figura 6. Relação entre comercialização e consumo da produção. Relationship between commercialization and consumption of production.

Quanto ao uso de agrotóxicos, a maioria dos entrevistados relataram não fazer uso de nenhum tipo de insumo, somente receitas orgânicas, fornecidas pela Empresa de Assistência Técnica e Extensão Rural (EMATER) aos agricultores familiares. Um dos motivos dos agricultores não utilizarem tais produtos, é a participação nos programas ${ }^{2}$ PNAE e PAA, que valorizam os produtos livres de agrotóxicos.

Em relação a utilização de agrotóxicos pelos agricultores familiares, evidencia-se que $80 \%$ dos agricultores relataram não utilizar nenhum tipo de agrotóxico. Entre as respostas

\footnotetext{
${ }^{2}$ Conforme Lei 11947/2009 e Legislação básica do PAA (2011) os agricultores são incentivados a produzir sem agrotóxico e recebem $30 \%$ a mais pelos produtos comercializados sem agrotóxicos.
} 
dos agricultores quanto à utilização de agrotóxicos, um relato chamou atenção em relação aos agricultores que utilizam veneno ${ }^{3}$ em sua produção:

“[...] tem que usar. Quem que diz que não usa nada, ou tá mentindo, ou não tira o sustento da lavoura, porque se não usar, não produz o suficiente. A estória de produção ecológica é muito bonito na televisão, porque pra nós não tem como produzir sem usar nada de insumos" (Agricultor 14 - Ponche Verde).

A fala deste agricultor remete a reflexão do quanto é importante trabalhar a perspectiva agroecológica nesta região, pois o policultivo preconizado pela agricultura agroecológica torna os ambientes menos suscetíveis a pressão de pragas e doenças, mantém o equilíbrio do agroecossistema, acarretando benefícios ao ambiente e ao homem (GLISMANN, 2001).

Quando não temos esse tipo de agricultura em pauta, assistimos os agricultores familiares manejarem com dificuldade suas unidades produtivas, pois tornam-se frágeis os recursos naturais e saúde humana (NASCIMENTO et al., 2019).

Enquanto isso, a maior parte dos agricultores afirmou não utilizar nenhum tipo de agrotóxico, uma vez que a Emater disponibiliza receitas de produtos orgânicos para serem utilizados na produção, outros, afirmam não ser possível obter uma boa produtividade sem o uso, mínimo que seja, de agrotóxicos.

"não podemos utilizar nada de veneno, só os que a Emater nos dá, e acho até bom assim, porque o gosto do nosso produto é diferente, daí a gente pode valorizar o preço dele. Tem gente que, mesmo se o meu produto estiver o dobro do preço do mercado, eles compram de mim, porque sabem que não tem nada de veneno." (Agricultor 15 - Pela gaúcho)

Quando questionado aos entrevistados sobre a obtenção de empréstimos e/ou financiamentos do governo, a maioria dos agricultores afirmou que não utilizam nenhum tipo de financiamento. Esse fato se deve à alegação, pelos agricultores, de que esse processo de acesso é burocrático, sobretudo na demanda de documentação. O Quadro 3 mostra os relatos dos entrevistados expressando os motivos que levam os agricultores a não buscarem o financiamento da questão.

Ainda discutindo os aspectos atinentes à diversificação produtiva, perguntamos aos agricultores se acham importante diversificar a produção no meio rural, todos responderam que sim, apesar de alguns relatarem não o fazer, ou por falta de espaço, ou por falta de mão de obra, ou por outros motivos. Dentre os motivos pelo qual os agricultores acham importante diversificar a produção, está atender aos pedidos dos consumidores e poder produzir de forma mais sustentável e que lhes garantam produtos o ano inteiro.

\footnotetext{
3 Utilizou-se o termo 'veneno', com relação aos agrotóxicos, por tratar-se de um termo mais usual entre os agricultores familiares.
} 
Quadro 3. Motivos que levam os agricultores familiares a não buscarem financiamentos. Reasons for family farmers not to seek funding.

\begin{tabular}{|c|c|}
\hline Excerto do relato & Identificação \\
\hline $\begin{array}{l}\text { [...] não, nunca tiramos, porque todo mundo fala que é } \\
\text { muito difícil, e a gente tem pouco estudo, não sabe muita } \\
\text { coisa, aí depende dos outros, do sindicato. }\end{array}$ & Agricultor 4: Ponche Verde \\
\hline $\begin{array}{l}\text { [...] não, é muita burocracia. Já tentei tirar o PRONAF, } \\
\text { mas eles pedem tanto papel, que nunca consegui juntar } \\
\text { tudo o que eles pediam. }\end{array}$ & Agricultor 5: Sanga Preta \\
\hline $\begin{array}{c}{[\ldots . .] \text { já tirei muitas vezes, mas o juro começou a ficar }} \\
\text { muito alto. Esse ano, comprei um trator, mas porque o } \\
\text { Banco ofereceu uma proposta muito boa, senão não tinha } \\
\text { feito. }\end{array}$ & Agricultor 9: Zona Periurbana \\
\hline $\begin{array}{c}\text { [...] esse ano vamos tentar tirar, para aumentar as estufas. } \\
\text { Queremos dobrar a produção. Tomara que a gente } \\
\text { consiga, porque todo mundo diz que tá cada vez mais } \\
\text { difícil. }\end{array}$ & Agricultor 11: Passo do Salso \\
\hline $\begin{array}{c}{[. . .] \text { agora faz tempo que não tiramos, estamos 'meio }} \\
\text { neutro' com o Banco, sempre devendo, renegociando } \\
\text { dívida. Mesmo porque não tem dinheiro, né! O Governo } \\
\text { tirou tudo. }\end{array}$ & Agricultor 14: Ponche Verde \\
\hline $\begin{array}{l}\text { [...] fiz um financiamento uma vez, para o gado e o tambo } \\
\text { de leite, mas agora não quero mais saber de Banco. } \\
\text { Paguei e encerrei tudo lá. Só querem tirar tudo de nós, } \\
\text { com tanto juro, acaba que a gente trabalha só pra eles. E } \\
\text { se não paga, eles vem e nos tiram o campo. }\end{array}$ & Agricultor 15: Pela Gaúcho \\
\hline
\end{tabular}

Ao perguntar aos entrevistados sobre seu conhecimento acerca do tema segurança alimentar e nutricional, os mesmos demonstraram que embora não tenham intimidade semântica com a palavra, ou seja, não se apropriam da palavra segurança alimentar e nutricional para justificarem suas ações que conduzem a isso dentro das propriedades, os mesmos o fazem instintivamente.

\section{CONCLUSÃO}

Os agricultores entrevistados possuem perfis semelhantes, com a predominância de propriedades cujas atividades de produção e comercialização são realizadas pelo casal, além de duas propriedades onde a proprietária trabalha sozinha. De maneira geral, todas as propriedades utilizam somente mão de obra familiar, até mesmo as de maior extensão de terra, sendo a forma de produzir quase que totalmente manual.

Todos os entrevistados utilizam a propriedade como fonte de renda, seja como única fonte, ou como complemento de renda, sendo que a comercialização se dá principalmente na feira livre municipal, nos comércios locais, direto ao consumidor e por meio dos programas 
PAA e PNAE, programas estes, onde os agricultores participam sem saber que tratam-se de programas criados com o intuito de garantir a Segurança Alimentar e Nutricional da população em geral.

O que ficou evidente neste estudo, é que embora esteja interiorizado em cada um dos agricultores entrevistados o que é segurança alimentar e nutricional, sendo inclusive muitas vezes, colocado em prática através da diversificação produtiva, estes não sabem expressar o seu significado semântico, fazendo pouca associação desta a importância dentro da perspectiva alimentar, dando maior ênfase aos motivos econômicos.

Como forma de dar sequência aos estudos nessa temática percebeu-se a importância de criar mecanismos de socialização e discussão desse tema no universo estudado, além de ampliar a investigação entre outros grupos de agricultores familiares.

\section{REFERÊNCIAS BIBLIOGRÁFICAS}

ALTAFIN, I. Reflexões sobre o conceito de agricultura familiar. Brasília, DF: CDS/UnB, 2007.

Disponível

em:

$<$ http://www.enfoc.org.br/system/arquivos/documentos/70/f1282reflexoes-sobre-o-conceitode-agricultura-familiar---iara-altafin---2007.pdf>. Acesso em: 30 out. 2017.

ALTEMBURG, S. G. N.; BEZERRA, A. J. A.; SCHWENGBER, J. E. Percepção Ambiental e Agricultura Familiar em Rede de Referência: uma análise sobre práticas agroecológicas e qualidade de vida. v. 1. Saarbrücken, Deutschland: Novas Edições Acadêmicas, 2015. 150 p.

BUAINAIN, A. M.; ALVES, E.; SILVEIRA, J. M.; NAVARRO, Z. Sete teses sobre o mundo rural brasileiro. Revista de Política Agrícola, Brasília, v. 22, n. 2, p.105-121, 2013.

BURITY, V., FRANCESCHINI, T., VALENTE, F., RECINE, E., LEÃO, M., \& CARVALHO, M. D. F. Direito humano à alimentação adequada no contexto da segurança alimentar e nutricional. Brasília: Abrandh, 2010. 204 p.

BRASIL - CONSELHO NACIONAL DE SEGURANÇA ALIMENTAR E NUTRICIONAL - CONSEA. A segurança alimentar e nutricional e o direito à alimentação adequada no Brasil. Indicadores e monitoramento, da Constituição de 1988 aos dias atuais. Brasília: CONSEA; 2010.

Disponível em: http://www4.planalto.gov.br/consea/publicacoes/publiucacoes-arquivos/a-segurancaalimentar-e-nutricional-e-o-direito-humano-a-alimentacao-adequada-no-brasil Acessado em julho de 2018.

BRUMER, A. Gênero e Agricultura: A situação da mulher na agricultura do Rio Grande do Sul. Estudos Feministas, Florianópolis, v. 12, n. 1, p.360, 2004.

COSTA, M. B.; MAINARDI, C. F. A ascensão das lavouras de soja no município de Dom Pedrito/RS. Revista da Jornada da Pós-Graduação e Pesquisa, Bagé, v. 1 , n. 1 , p.411427, 2017. 
EMPRESA BRASILEIRA DE PESQUISA AGROPECUÁRIA - EMBRAPA. Indicações técnicas para a cultura da soja no Rio Grande do Sul e em Santa Catarina: safras 2014/2015 e 2015/2016 - 2014. Pelotas: Editora Embrapa, 2014. 127p.

FERREIRA, M. A. J.; WETZEL, M. V. S.; VALOIS, A. C. C.; MACEDO, J. El estado del arte de los recursos fitogenéticos en las Américas. Agrociencia, Montevideo, v. 9. , n. 1-2. , p.85-90, 2005.

FUNDO NACIONAL DE DESENVOLVIMENTO DA EDUCAÇÃO - FNDE. Dados da agricultura familiar. 2018. Disponível em: <http://www.fnde.gov.br/programas/pnae/pnaeconsultas/pnae-dados-da-agricultura-familiar>. Acesso: 08 dez. 2018.

GIL, A. C. Métodos e técnicas de pesquisa social. 6. ed. São Paulo: Atlas, 2008. 128 p.

GIL, A. C. Como elaborar projetos de pesquisa. São Paulo: Atlas, 1991. 45 p.

GLIESSMAN, S. R. Agroecologia: processos ecológicos em agricultura sustentável. Porto Alegre: UFRGS, 2001. 653 p.

INSTITUTO BRASILEIRO DE GEOGRAFIA E ESTATÍSTICA - IBGE. Panorama das Cidades. Disponível em: 〈www.ibge.com.br〉. Acesso em: 10 nov. 2017.

MANIGLIA, E. As interfaces do direito agrário e dos direitos humanos e a segurança alimentar. São Paulo: UNESP Cultura Acadêmica, 2009. 277 p.

MORAES, R.; GALIAZZI, M. C. Análise textual discursiva. 3. ed. Ijuí: Editora Unijuí, 2016. $264 \mathrm{p}$.

MATTE, A.; SPANEVELlO, R. M.; ANDREATTA, T. Perspectivas de sucessão em propriedades de pecuária familiar no Município de Dom Pedrito - RS. Holos, Dom Pedrito,

v 31. ed.1, p.1-16. 2015. Disponível em <www2.ifrn.edu.br/ojs/index.php/HOLOS/article/ view/1964/pdf_157>. Acesso em: 16 nov. 2017.

MINAYO, M. C. S. Ciência, técnica e arte: o desafio da pesquisa social. In: MINAYO, M.C.S. Pesquisa social: teoria, método e criatividade. Petrópolis: Vozes, 1996. cap. 2, p. 0929.

NASCIMENTO, S. G.; BECKER, C.; SILVA, F. N.; CALDAS, N. V.; ÁVILA, M. R. Produção agroecológica e Segurança Alimentar e Nutricional (Brasil). Revista de Ciências Agrárias, Portugal, v. 42, n. 1, p.294-304, 2019.

NIEHOF, A. The significance of diversification for rural livelihood systems. Food Policy, Bologna, Italy, v. 29 , n. 4, p.321-338, 2004.

RIBEIRO, C. M. Pecuária familiar na região da campanha do Rio Grande do Sul. Série Realidade Rural, Porto Alegre, v. 34, p.11-45, 2003.

SOUZA, J. T. A.; FARIAS, A. A.; CORREIA, F. G.; DA COSTA, C. A. G.; OLIVEIRA, S. J. C. Associativismo, assistência técnica e extensão rural como políticas públicas para a geração de desenvolvimento sustentável na agricultura familiar em Taperoá, PB. Revista Brasileira de Geografia Física, Pernambuco, v. 8, n. 2, p.303-308, 2015. 